\title{
The Tablet as a Classroom Musical Instrument
}

\author{
By Adam Hart*
}

\begin{abstract}
Music education is rightly recognised as an important part of children's social, creative and academic development. Current UK policy holds that all children should have the opportunity to learn a musical instrument and have access to quality music education. In practice, however, many primary schools do not have the resources and guidance to deliver this, and with the pressures of literacy and numeracy attainment, the more advanced aspects of music education, such as notation and theory, often seem unachievable goals. Primary schools increasingly utilise tablet devices, such as iPads, to improve interactivity, engagement and accessibility in other aspects of learning, but this approach is yet to be widely adopted within music classes. As part of a wider research project funded by the Arts and Humanities Research Council, this study examines the effectiveness of such tablet applications in a Year 5 class on performance and composition, and assesses how this approach might function on a wider level. All children have the right to a music education which allows them to develop their expression and understanding. The modes of interaction and representation with which children are accustomed from regular use of tablets may help to ensure that this is present in every music class.
\end{abstract}

Keywords: composition, experiential learning, music, performance, technology.

\section{Introduction}

One area in which the quality of education might be said to have benefitted from the application of technology over the past few years is with the adoption of the touchscreen tablet as a classroom learning resource. There are a number of factors that make tablets particularly suited to classroom learning. Being generally more affordable and portable than laptop computers and being immediately accessible without booting up or logging in, tablets are convenient, providing immediate access to a great deal of interactive and versatile functionality. Inexpensive models and operating systems generally have the same range of functions and applications available as higher-range models, albeit with perhaps less memory or a lower quality camera, so schools can obtain a stock of tablets as a relatively modest financial investment. Research suggests that the use of tablets in primary schools is increasing at a substantial rate, while many countries are engaged in large scale deployment schemes to increase the availability of tablets in education (Clarke \& Svanaes, 2014; 2015). Some schools are already employing one tablet per pupil (Clarke, Svanaes, \& Zimmermann, 2013) and the emergence of "bring-your-own-device" in some secondary schools (Tierney, 2012; Pegrum Oakley, \& Faulkner, 2013; Sangani, 2013; Santos, 2013) and primary schools (Song, 2014; 2016) is likely to increase the prevalence of

\footnotetext{
${ }^{*} \mathrm{PhD}$ Candidate, University of Salford, UK.
} 
personal device in the classroom. With the growing trend of young children utilising the personal devices of parents and guardians, these are tools with which children are increasingly comfortable and engaged (see Marsh et al., 2015). Their use in the classroom can ensure that more children have access to such resources from an early age and enabling them to learn how these powerful and versatile devices can be tools of inquiry, creativity, and socialisation.

Tablets have been widely incorporated into the teaching of core subjects, such as literacy and numeracy. Numerous applications and websites are available which make games out of spelling and sums, and allow different users to compete against one another. Science and humanities subjects have benefitted from the accessibility of web browsing and video clips, as well as interactive resources which can help children to engage with concepts normally requiring specialist equipment, such as conducting a chemistry experiment or measuring weather systems. The touchscreen function has been particularly useful for art lessons, with a massive variety of drawing, painting and image editing applications being freely available. Most tablets are also easy to customise in terms of both layout and mode of interaction, meaning that children can personalise their own virtual environment according to their interest and educational requirements. Modes of input and output can be customised to assist students who might otherwise have difficulty interacting with the device, such as magnifying the screen for partially-sighted students, and even incorporating voice operation or eye-tracking applications as input methods.

Relatively little attention, however, has been given to the ways in which the tablet may benefit music lessons. There are past examples of music education failing to keep pace with technological trends: In a 2012 national survey on music in schools, Ofsted reported "... insufficient improvements in the quality of learning through the use of technology" (p. 54). Research from 2013 suggests that children are using technology for music-related activities at home far more than at school (Daubney \& Mackrill, 2013). It is therefore important to examine how relatively new technologies such as the tablet may be of value to music education. While much research is needed in this area, this study addresses some of the ways in which the tablet might present a useful resource for performance and composition, and how this functions within the dynamic of the music classroom.

\section{The Importance of Musical Opportunities in the Classroom}

The 2011 National Plan for Music made the argument that a quality music education is an important part of children's individual and social, as well as academic, development, and that it should therefore be available to all from a young age (DfE, 2011, p. 2-4). This was to be achieved by referring responsibility for the provision of quality music education in the UK to 121 music hubs, which give every child the opportunity to learn an instrument or sing. However, this has failed to provide clear benefits to classroom teaching. Most of the teachers working for hubs are accustomed to individual instrumental lessons rather than curriculum schemes of work and whole class teaching (MU, 2014, p.3). Mounting 
pressures of core subjects, as well as funding cuts to arts and other non-core subjects, mean that standards for music education are increasingly becoming an extracurricular matter, which presents a problem: Those children without access to instruments, or the means to pay for individual tuition, do not have the opportunity available to them. If schools have no drive to improve the quality of musical learning in the classroom, enthusiasm for musical learning among students may go undeveloped or unanswered, and having no obligation to access music hubs, those in the most deprived areas, where the pressures of attainment targets and funding cuts are most keenly felt, fail to do so. Consequently, the poorest in society continue to be let down with regard to music education.

It is not enough to simply make opportunities for musical progression available, as evidenced by the low uptake of music as a course of study when it becomes optional at key stage 4 (Little, 2009; Ofsted, 2013, p.12). As the National Curriculum states:

"A high-quality music education should engage and inspire pupils to develop a love of music and their talent as musicians, and so increase their selfconfidence, creativity and sense of achievement" (DfE, 2013, p. 1).

It follows then that a quality music education for all must begin in the classroom as a valued component of formal education, so that interest in later opportunities, as well as receptiveness to the more challenging aims of the curriculum, is an eventuality afforded to all students:

"It is only through 'classroom music' that we can ensure that music education is accessible to all, and not an elitist pastime available only to those that can afford to pay for it" (Daubney \& Mackrill, 2015, p. 249)

A higher quality music education for all may lead to greater progress at key stage 3, which has been identified as a period of formal education in which students make the least musical progress (Hallam, Creech, \& McQueen, 2017, p.2). This may then, in turn, lead to greater rates of uptake for key stage 4 music and beyond. This may also have lateral value, as the social and creative benefits of a quality music education help students to excel in other ways. If we are to ensure, as the National Plan for Music states, that "... more children have access to the greatest of art forms, but that they do better as a result in every other subject" (DfE, 2011, p. 4) then we must look for ways in which early music education can be augmented in the classroom.

\section{What Tablets Can Offer Musical Learning in the Classroom}

The use of personal devices in the classroom is a fairly recent emergence, and yet one which has grown with considerable momentum. Consequently, the effectiveness of such devices in aiding learning within the core subjects is still a somewhat inconclusive matter, though one of current relevance. Research 
comparing use across different curriculum subjects is particularly scarce, and we are only starting to gather evidence on how tablets and other personal devices may be beneficial within non-core subjects such as music: Riley (2013) documents the various uses of the iPad in music lessons. Criswell (2011) examines teacher perspectives on using the iPad for performance and composition. Most reports focus on the practices of innovative teachers, in an individual case study basis. Specific examples can be helpful, as the vast amount of apps and possibilities may make the use of tablets for music seem daunting, especially to non-music specialists. Riley (2016) suggests six apps that may be used for classroom composition with young children, and provides sample lesson plans. Some of these apps offer intuitive interactions with the touchscreen as ways of manipulating timbre, such as Singing Fingers and Brian Eno's Bloom app. Ruismäki, Juvonen and Lehtonen (2013) document a Finnish music teacher's use of the iPad for practical learning, noting the scaffolding possibilities of the Garage Band app (p. 1091-2).

In particular, research is needed to explore how tablets might assist with the delivery of curriculum. At just 400 words in length, the 2013 National Curriculum for Music at key stages 1 and 2 sets rather complex and demanding aims requiring a considerable degree of musical and pedagogic specialism, but offers no guidance as to how these might be achieved. We are told that students should "perform in solo and ensemble contexts... with increasing accuracy, fluency, control and expression' and "improvise and compose music for a range of purposes using the inter-related dimensions of music" (DfE, 2013, p. 2). These are aims that are challenging to both execute and measure, so it is important that sufficient support and resources are available, especially for the teachers without specialist musical training who deliver around two thirds of primary school music lessons (Ofsted, 2012, p.18). Lack of confidence in teaching music among generalist teachers is a persistently reported issue (Holden \& Button, 2006; Seddon \& Biasutti, 2008; Hallam et al., 2009; Russell-Bowie, 2009; Stunnell, 2010; de Vries, 2013; Garvis, 2013; Biasutti, Hennessy, \& de VugtJansen, 2013) though many primary schools lessen these pressures with subscriptions to Charanga Music World, an online scheme of work which breaks down curriculum aims into sequential lessons and accessible concepts, and similar multimedia resources.

The curriculum now also states that key stage 2 students should "use and understand staff and other musical notations" (DfE, 2013, p.2), a challenging aim which may be made more achievable using the tablet as an interactive score (Wyatt \& Hope, 2013). Alternative interactive notations can similarly provide a scaffolding platform to help students understand pitch and rhythmic relationships, as well as other musical parameters. The "tuneblocks" system, invented by Jeanne Bamberger and utilised in the software Impromptu (Bamberger \& Hernandez, 2000), breaks melodies into manageable and meaningful fragments, allowing young children to engage with musical form and structure:

"... highly aggregated, structurally meaningful entities such as motives, 
figures and phrases... are the "units of perception" - the elements that novices have ready access to, their focus of attention" (Bamberger, 1996, p. 42)

The ability to provide audience-friendly representations of complex concepts - "objects-to-think-with", to use Papert's term (1980, p. 11) - is a clear benefit of digital media. Where such assistive avatars are interactive via input devices, the capacity to connect user actions to meaningful outcomes, or transparency (Fels, Gadd, \& Mulder, 2002), can be achieved. Compared to the mouse-operated computer, the touchscreen tablet offers a far more natural and kinaesthetic mode of interaction, as well as a more portable hardware system. This means that the scaffolding possibilities of "objects-to-think-with" can be harnessed within much more practical and experiential contexts. Apps which follow this design approach may be very useful within early-years music education, where students may have a more limited musical capability and understanding, but will still benefit from practical musical experience. According to Ofsted, "... evidence showed, very clearly, that children made the most musical progress when they were taught in music rather than about music" (2012, p.46), a finding which resonates with Paynter's assertion that "... making music is more important than musical information" (1982, p.xiiii).

The resources and apps discussed may assist with musical understanding and generate processes which allow students to create musical structures. There is less research on how iPads might be used for ensemble performance in the classroom, a specific aim given in the National Curriculum. Students must have the opportunity to perform music in groups, and develop their attention to expression. Williams (2014) has argued that the iPad can function as an expressive musical instrument:

"When used to make music, the iPad is a musical instrument. It can be performed well or poorly. It takes practice to build performance technique on it. It will do nothing without musicianship, creativity, and imagination supplied by a person. It has musical limitations just like any instrument, but in the right circumstances, it can be used to make amazing music." (p. 97)

As portable tools with a tactile mode of interaction, tablets might function like any other musical instrument. While funding cuts to the arts are likely to lead to fewer instruments being available in the classroom, the usefulness of tablets across a range of subjects means that students are more likely to have access to tablets than instruments. If we can promote the use of the tablet as a musical instrument, we may ensure that more children have access to a practical music education.

Instrument stocks in primary schools have generally consisted of miscellaneous inexpensive percussion instruments, along with rudimentary melodic instruments such as the recorder. Policies such as the Wider Opportunities and First Access schemes have had some success in bringing a greater range of instrumentation to the classroom, though this has been beset by various logistical and financial barriers, mainly attributed to the transportation and setting up of 
instrument stocks (MU, 2014, p. 3). The National Curriculum tells us that children should "play tuned and untuned instruments musically" from key stage 1 (DfE, 2013, p.2). Access to tuned instrumentation in the classroom must then be a more frequent opportunity, and while policies like First Access should continue, schools cannot rely completely on this for instrumental provision. The tablet can provide a scaffolding opportunity in the classroom by emulating a range of tuned and untuned instruments. In addition to many keyboard and piano interfaces, free apps to emulate the playing interface and timbres of instruments such as guitars, concertinas, drum kits, gamelans and Theremins are immediately accessible and plentiful. The capacity for customisation and communication between devices also opens up possibilities for musical performance unique to digital instruments.

Creativity within digital media is increasingly a source of learning activities for younger children. Coding environments aimed at the young, such as Scratch and Barclay's Code Playground are being used to develop games and simple programmes in the primary ICT classroom (Wilson, Hainey, \& Connolly, 2012; 2013; Smith, Sutcliffe, \& Sandvik, 2014). In addition, the design of apps is becoming a more user-friendly process, as their widespread use in our everyday lives means that more people want to try to make their own. Various online and software programmes are available to scaffold app development for novice programmers. Programmes such as MobMuPlat and TouchOSC allow the user to generate simple touchscreen interfaces, which can then run as standalone applications or communicate with other devices. Given these examples, it is entirely reasonable to assume that children could soon make and run their own apps in school. Under such circumstances, the tablet would be of enormous benefit to music lessons, as children could make and play their own digital instruments. It is therefore important that we look at how children respond to tablets within music lessons, how they function within performance and composition contexts, and also what limitations they might present.

\section{Methodology}

This study consisted of two afternoon music sessions conducted with the Year 5 class of a primary school in the North West of England in December 2016. The purpose of the study was to examine some applications of the tablet in facilitating music performance and composition activities as part of the curriculum, without reliance on specialist musical or instrumental training. Data was primarily collected by means of observation. An audio recording was made of the lessons, and photographs were taken by the class teacher. This research is a case study of the outcomes of these lessons - further case studies will be conducted to investigate conclusions emerging from these findings. The study also has links to action research, being focused upon the implementation of new technological approaches within this specific learning environment, supported by qualitative observation of outcomes. As this is a relatively new research area, and as academic opinion is still divided on inherent benefits of 
tablets and other mobile devices in education (Clarke \& Svaneas, 2015, p. 3), any research of this nature is likely to be exploratory, with links to grounded theory. In this case, the tablet has been appropriated with existing pedagogic theory, and functions as a scaffolding resource, presenting the musical materials in a manner that is easy to comprehend and interact with. This is intended to make the performance task more accessible by providing a common reference point, and to facilitate group engagement with musical ideas which arise from performance, an approach informed by social constructivism (Vygotsky, 1962).

Despite the short duration of the study and small sample size, we hoped to gain some insights that might help us to answer the following questions, which draw from the language of the National Curriculum:

- How might the tablet function within the dynamic of the classroom, in terms of facilitating "performance in solo and ensemble contexts"?

- How might the tablet be used to encourage "increasing accuracy, fluency, control and expression"?

- How might the tablet allow pupils to engage with the "inter-related dimensions of music" in their performance and composition?

- How might the tablet utilise alternative modes of representation to lead pupils toward a greater understanding of staff notation?

As the study forms part of a wider research project, which aims in part to develop new resources or approaches for musical learning in the classroom, bespoke iPad interfaces tailored to the lesson content were produced. These were made with MobMuPlat, a standalone application which runs custom interfaces utilising the functions of the iPad, and programmed using the opensource coding language Pure Data. These interfaces were designed to facilitate ease of use in ensemble performance contexts.

The study took place in a primary school over two Friday afternoon sessions of 90 minutes, taking place a week apart. The Year 5 class consisted of 27 students, 16 girls and 11 boys. No pupils were identified as requiring special assistance, and none of the pupils took extracurricular music lessons to learn an instrument or sing. While I led teaching of the lessons, the class teacher was on hand to provide assistance. Fifteen iPads were available for use, meaning that most of the students had one device between two individuals. One concern before the study was that the iPads would not be sufficiently audible through the built-in speakers, while separate amplification for each iPad was an unreasonable solution due to cost. Different methods were implemented to solve this issue during the course of the study.

The Year 5 teacher described the usual activities of a music lesson:

"The school accesses the 'Charanga Musical School' website which provides a breakdown of objectives for each year group along with a range of practical resources for the children to take part in. The activities that the children take part in include singing and using percussion instruments to help them perform a composition". 
In music lessons at this time of the year, the class would usually use Charanga to learn and sing Christmas songs, perhaps accompanied by percussion instruments. Being a Catholic school, nativity plays were an annual feature, and the performance of Christmas carols a popular music activity in December. The Year 5 teacher felt that this would present a good opportunity to try some new approaches to performance of songs with which the class were already familiar. Drawing from the National Curriculum, the main outcomes for this lesson series were to facilitate solo and ensemble performance of Christmas songs using the tablets alongside percussion instruments and voices, and to demonstrate an attention to expressive functions, as well as the "inter-related dimensions of music". In the second lesson, a similar approach was used to facilitate performance and composition.

\section{Lesson 1}

Objective: To perform a Christmas song in groups, and to change the mood using the "inter-related dimensions of music".

The purpose of the first lesson was to create variations in performance of the song, changing the "mood" with attention to musical dimensions, and providing opportunities for discussion and reflection on how they function individually and in combination. Certain dimensions could be expected to be addressed more readily on an individual basis, being fairly instinctive to comprehend and manipulate. In particular, dynamics and timbre might fit into this category. Other dimensions, by contrast, might require a degree of coordination and communication between players to properly execute, such as tempo and texture. The remaining dimensions of tonality and structure - and perhaps to some extent, pitch are more related to composition and arrangement, and could be expected to require a greater degree of planning and creative exploration to address.

In order to quickly reach a point where the class could confidently perform the melody, I decided to use Bamberger's concept of "tuneblocks" in my interface design (Bamberger, 1996; Bamberger \& Hernandez, 2000). The song chosen for this lesson was "Little Donkey", a Christmas carol which the class knew from its usual inclusion in their school nativity plays. This was a particularly suitable piece to display in tuneblocks due to its regular phrasing pattern, which includes a recurring phrase with an easily recognisable rhythmic and melodic pattern (see Figure 1). I felt that the chorus of the song would provide an opportunity to explore some contrasting dimensions, changing from major to minor chords and having melodic contour and lyrics of a more rousing nature. Also, the midbar chord changes might present more of a challenge than the steady changes of the verse. I saw these as potential scaffolding activities between the performance of the verse and a more creative arrangement-based exercise. 
Figure 1. The Verse of "Little Donkey"

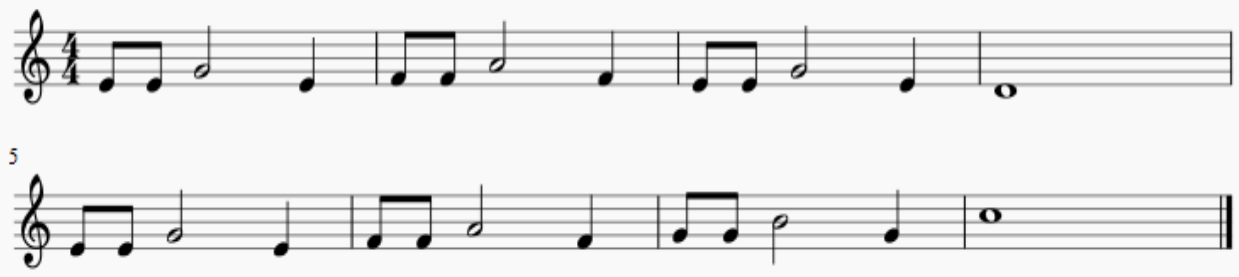

An interface was made in MobMuPlat that divided each bar into colourcoded tuneblocks, with each colour corresponding to the accompanying chord. The notes were represented as rectangles arranged into place according to their rhythmic position within the bar and pitch relationship to the rest of the melody. When one of these buttons was touched, the corresponding note of the melody sounded. Therefore, the player simply had to move consecutively through these buttons following the rhythm of the song. A second window showed the tuneblocks for the chorus. By swiping left or right, the player could move to the previous or next screen (see Figure 2).

Figure 2. The Verse and Chorus of 'Little Donkey' in iPad Tuneblocks

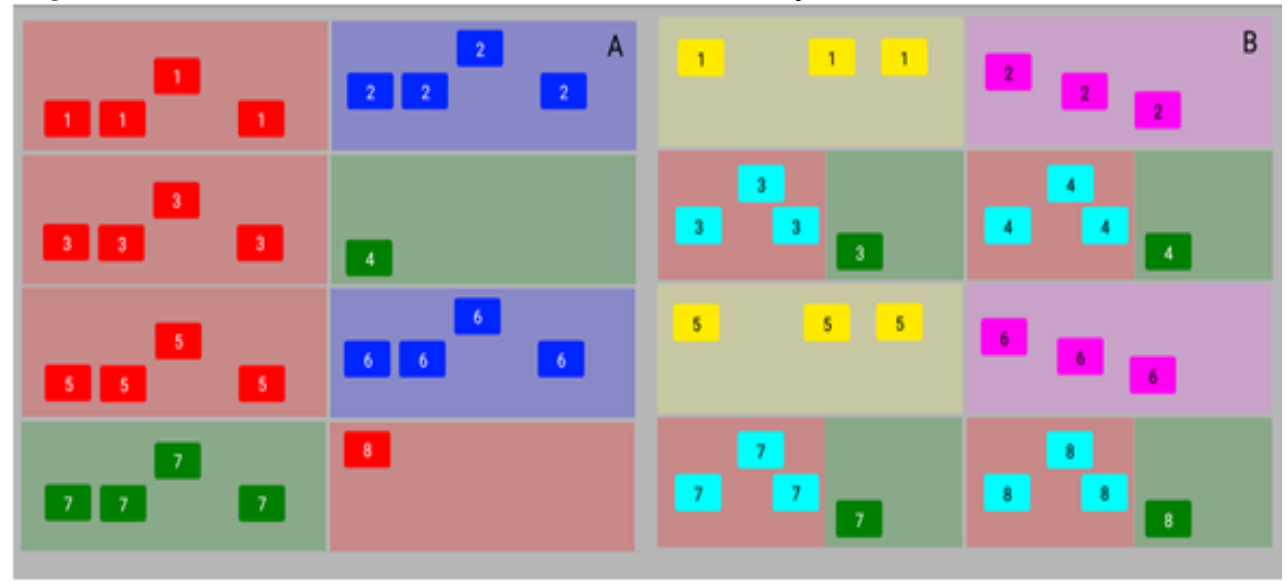

Figure 3. The iPad Chord Interface

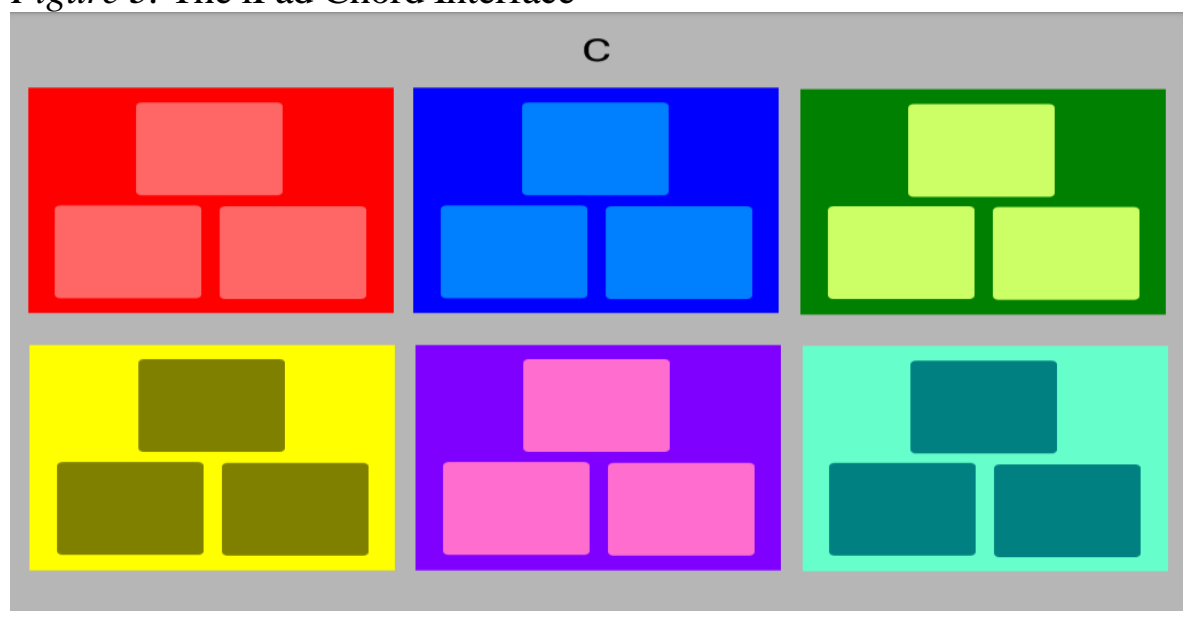


A third screen showed six coloured boxes representing the chords of the song (see Figure 3). These were colour-coded to match the corresponding tuneblocks, and each contained three buttons which played the root note, third and fifth of the triad chord in question. I decided to break the chord into separate notes rather than use a single button so that the pupils could play broken chords and come up with their own accompanying patterns. I considered arranging these in a vertical rather than horizontal line, to match the arrangement of pitch in the tuneblocks, but felt that this would require the hand to be angled at an awkward position. In my experience of teaching keyboards, novice learners often play chords using the three middle fingers rather than the more conventional thumb, middle finger, little finger position, so I decided to arrange the chords on the interface to match this triangular formation. This more naturally lends itself to touchscreen multi-finger performance, where the thumb is less likely to be used due to its different angle and shorter length compared to the other fingers. The final screen allowed the player to choose an instrumental voice for each of the three "performance screens", as well as setting the volume. A general MIDI sound set was used for sound sources.

The plan for the lesson was to divide the class into five total groups; three groups of 5 and two groups of 6 . Each group had three iPads and an assortment of percussion instruments, and was allocated an area of the room in which to work. While planning the session, a number of obstacles were faced with regard to amplification. The iPads would need to be sufficiently audible over percussion instruments, and it was clear that the built-in speakers would not transmit a loud enough signal. Transmitting the three iPads of each group to a Bluetooth speaker was considered, though the models available could only accept one device at a time. Ultimately, the setup had to be reconsidered. A laptop was connected to each of the five speakers, containing the set of general MIDI sound sources. The iPad interfaces were then edited so that, as well as playing notes directly, they could transmit Open Sound Control (OSC) messages over a wireless connection to the laptop. Thus, within each group, the sounds triggered by any of the three iPads were played through their paired laptop and out of the speaker. Though the school had a Wi-Fi connection, it was decided that a separate router be brought to minimise any possible issues with connectivity. In this way, the setup and equipment required to amplify the iPads became quite complicated and extensive.

The plan for the lesson was as follows:

1. Students are put into pairs, with an iPad each, and are given time to explore the interface and work out the song. Groups can then be chosen to identify and play part of the song.

2. Questions: "What is the song about?" "How fast should it be?" The class are likely to suggest a slow, plodding tempo to suit the pace of the tired donkey. This generates a discussion about how musical dimensions can be used to improve a performance. 
3. Half of the class clap the suggested tempo, while others play the melody. Question: "In each block of melody, how many times do we clap?" This introduces the idea of a bar of four beats.

4. Each group then plans and rehearses a performance of the song using iPads and percussion instruments. The teacher moves around the room asking further questions to each group to introduce other musical dimensions, e.g. "What kind of instrument would suit this part of the song?" "How might percussion instruments be used to fit around the melody?"

5. Groups then add a new verse which takes the song in a new direction. They are asked to come up with a possible new lyric and to represent this with a change in musical features; e.g. "little donkey, little donkey, time to go to sleep..."

6. Performances by each group take place at the end of the lesson, with other groups asked to comment on how musical features were used to create a mood for the song.

This lesson was planned to allow as much time as possible for practical musical learning, such as performance and composition, followed by reflection and discussion focusing on the musical dimensions.

\section{Results}

It was clear from the start of the lesson that the students were enthusiastic about using the iPads, and that they were generally confident about operating them. This was a characteristic shared by both boys and girls. Both the teacher and I ensured that everyone had the opportunity to use an iPad, and the students worked well in groups. No instances of arguing over iPads or instruments were observed. The setup used for this lesson had, as discussed, reached a more complicated level than originally intended. Equipment was set up during the lunch break preceding the lesson, though it was agreed by both the teacher and I that these requirements would be to demanding for regular use, and that a more efficient solution should be found for the next lesson. The use of OSC communications proved highly stable, as each iPad instantly connected to the host laptop and speaker and the transmission of wireless communications remained unbroken. This allowed the students to rehearse and perform in groups using a combination of iPads and percussion instruments. However, further issues with this setup became apparent during the rehearsal session, as some students complained of being unable to hear what they were doing as the noise level increased. Students were tending toward turning the volume of their iPad as loud as possible to achieve clarity, and consequently other students had to follow suit to maintain a consistent level. With three iPads playing through each speaker, it also emerged that some students were struggling to identify which sounds were being created by them. I attempted to resolve this by emphasising the importance of communication in group performance, and demonstrating how a performer 
should pay attention to the actions of their fellow performers in addition to their own. This went some way toward resolving the issue, though it was still apparent that the setup used was largely unsuitable for this kind of lesson.

The tuneblocks interface proved effective, as all students were able to play and identify the carol. This allowed us to begin discussing performance features immediately following the starter activity. Students were keen to answer the questions with practical demonstrations using the iPad:

Me: So if the donkey is feeling tired in the song, how fast should we play it?

Student: It would be like, slow, like... [plays the first two bars at a deliberate, plodding pace] ... instead of... [plays at a franticly accelerated tempo]

This led to interesting developments during the group rehearsals, where students were engaged with capturing the mood of the song through interpretation of musical dimensions, or altering the composition in some way. I pointed out that percussion can be used to augment the mood of the song by finding interesting rhythms, perhaps filling in gaps in the melody, or taking a rhythm from a different song. This meant that the arrangements developed interesting textures as the lesson unfolded. Likewise, performance of the main melody was left to one iPad at a time in all groups, with others using the interface to provide some form of accompaniment, again supported by the use of colour-coding in the tuneblocks layout. In some cases, performance of the melody was divided between different players at different points, allowing students to switch between different roles. All the groups were engaged in discussion about these ideas, and were eager to perform when the opportunity arose.

Most performances were characterised by the use of clopping, steady rhythms on wooden percussion instruments during the verse, and tambourines or bell-like instruments during the chorus. The chorus was also generally louder than the verse. Both of these features were identified as being suitable due to the lyrics - the plodding, tired donkey described in the verse, and the contrasting chorus of "ring out those bells...". One group added a new set of lyrics for an additional verse:

Little donkey, little donkey, sleep and dream tonight,

Little donkey, close your eyes and go to sleep so tight,

This was played using a low-pitched bass sound, with a quiet tinkling of bells and bell-sounds from the other iPads. The low pitch was characteristic of the slumping, drowsy donkey, contrasted by the high tinkling bells representing the stars above.

Three of the five groups used the whiteboards on their tables to make notes on the structure of the performance, regarding who would be doing what, or the notes they wished to play. This was undirected and emerged as they experimented with different ways of using the iPad other than playing the melody. Two of the groups changed the rhythm of the melody, wanting to achieve a more upbeat mood (see Figures 4 and 5). 
Figure 4. Rhythmic Variation on the Melody of "Little Donkey" adding an Additional Note at the Third Beat of Each bar

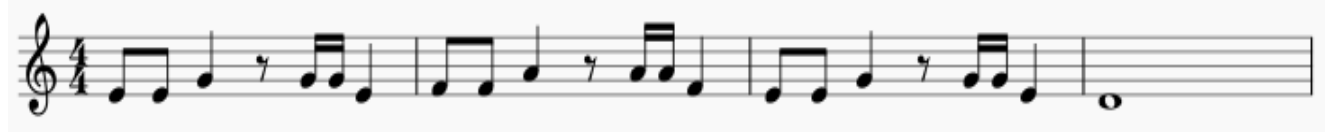

Figure 5. Rhythmic Variation on the Melody of "Little Donkey" in Semiquavers

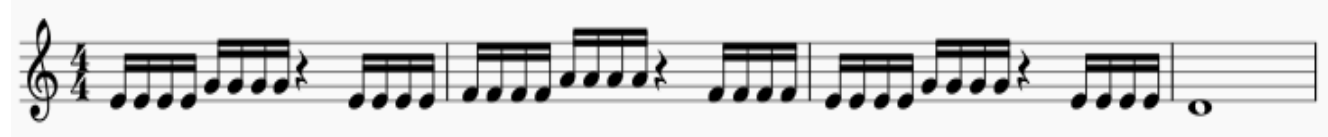

In the second group, this formed part of an intriguing structure. The verse had a tremolo-like effect, achieved by playing each note multiple times in rapid succession, using a guitar timbre. This was followed by the chorus, utilising bell sounds in the same manner as other groups. Finally, this was followed by an improvisation between two iPads, selecting notes at random within the colour-coded structure set out by the tuneblocks.

Figure 6. Melodic Variation Following the Same Rhythmic Pattern

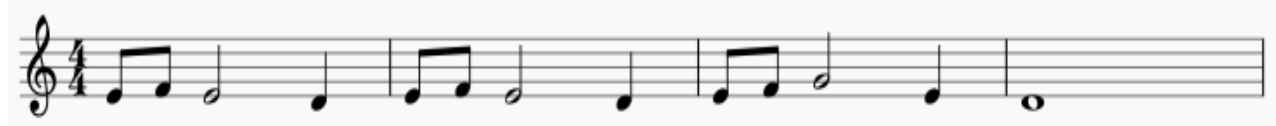

One group used notes from different tuneblocks to create a new melody to the same rhythm (see Figure 6). This was followed by the normal melody of the chorus, while the rhythm of the verse continued to be played using the percussion instruments. This created an effective and interesting textural contrast. Another group followed the tuneblock structure, but used this to create a new rhythmic and melodic pattern, while preserving harmonic structure (see Figure 7).

Figure 7. New Rhythmic and Melodic Sequence Following the Same Harmonic Structure

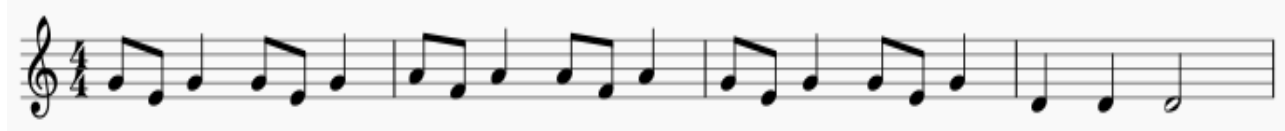

The final group diverted the most from the original arrangement. A cello sound was used on all iPads, and only the screen showing the triad chords was used. Performance consisted of chords of long duration, alternating with broken chords moving in different directions, accompanied by a steady rhythm. The other students were particularly enthusiastic in commenting on this performance, and in finding comparisons or ways to describe it:

"That's definitely not 'Little Donkey' no more!"

"It's like a drama... it sounded like the music to 'Batman' or something...."

"It was like an organ weren't it?" 
This led to discussion on the qualities of dramatic music, and of the suitability of instruments like the cello and organ to creating this kind of mood, being capable of low pitches and long sustained durations.

\section{Lesson 2}

Objective: To compose and perform a Christmas carol

The National Curriculum states that children should "compose for a range of purposes using the inter-related dimension of music" (DfE, 2013, p.2). The purpose of this lesson was to explore how a Christmas carol is constructed, and to compose a new one based upon these guidelines. To avoid the increasingly complex setup that was eventually used for the previous lesson, the class was divided into pairs rather than groups, with each having one iPad. Headphone splitters were used to send the output to two pairs of headphones, while a single Bluetooth speaker was brought for the purposes of performance, as only one iPad would need to be used at a time. Two spare speakers were brought, however, in case the opportunity for multiple iPads to perform together arose.

Use of iPads was simplified to a single interface, again made in MobMuPlat. This consisted of eight numbered and coloured keys, corresponding to an octave of the major diatonic scale (see Figure 8). These keys illuminated when pressed, and played high-quality instrument samples. Clipart images were used to show the selected instrument, and volume could again be altered using a dial. The screen was divided into two identical sections, allowing students to select different instruments or volume settings and easily switch between the two. On a second screen, the upper section was flipped upside-down, so that students had the option to play the iPad in pairs, by laying it flat on a table and sitting on either side of it.

\section{Figure 8. The iPad Interface used for the Second Lesson}

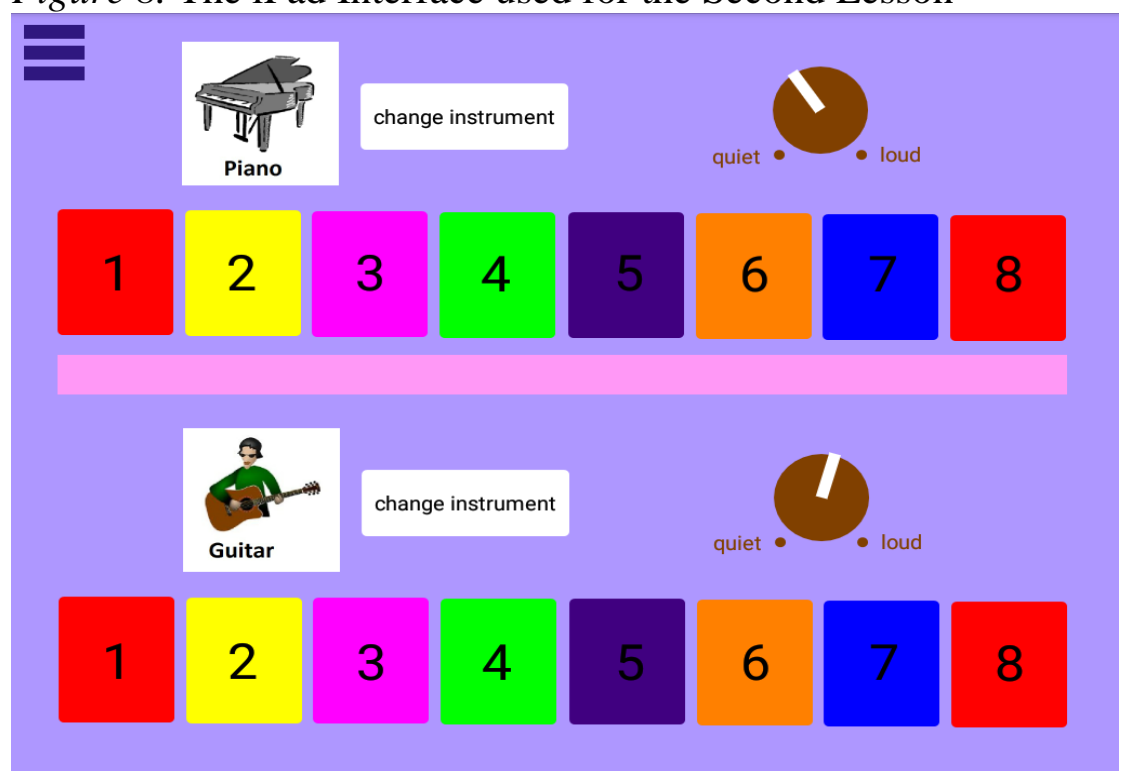

Source: Clipart image of piano taken from http://bit.ly/2wkBkbh, clipart image of guitar taken from http://bit.ly/2gl1DKp. 
Having found the tuneblocks approach to be effective in breaking down a melody into manageable sections, and also finding that the students could follow this with minimal direction, I decided to make a game out of the idea that could serve as a starter activity. Christmas carols were again broken into bar-long tuneblocks, but would be mixed up. The class would then have to work out how to play them, identify the song, and arrange the tuneblocks into their correct structures. To use carols which would contrast in mood to "Little Donkey", and which prove more challenging to work out and play, I decided on "Jingle Bells" and "Rudolph the Red Nosed Reindeer". This would allow the students to use musical dimensions more characteristic of a sprightly mood, and the more complex rhythmic groupings and melodic contours would prove more of a challenge. The notes of the melody were numbered and colour-coded to match the iPad interface.

My original intention was to make a new tablet interface in which these tuneblocks could be arranged, but ultimately I decided to print these off onto pieces of card, to be put back together like a jigsaw puzzle. The students could later turn the cards over, and compose their own tuneblocks on the blank side, arranging these into a larger composition.

The plan for this lesson was as follows:

1. Students work in pairs, with a set of cards and an iPad, to put an entire tune together. Those who complete this task quickly are given percussion instruments and asked to plan a performance using the musical dimensions, in the same manner as in the previous lesson.

2. Selected pairs are then asked to perform the melody, followed by a discussion on what musical characteristics are commonly found in Christmas carols.

3. The class writes a short carol together. They are asked for a sentence that has something to do with Christmas, which is then chanted to fit a fourbeat bar. A student is then asked to improvise a melody to this rhythm using the iPad. The class write another three tuneblocks in the same fashion to complete the song.

4. Each pair then writes their own carol. The teacher moves around the room to assist, and remind how musical dimensions might be used to create a mood.

5. The carols are performed at the end of the lesson, with the rest of the class commenting on how a Christmas mood was created using the musical dimensions.

This was the last lesson before the Christmas holiday, so the ways in which musical dimensions might be used to create a seasonal mood were a prominent feature of the lesson. As with the previous lesson, the class started with a practical music-making activity, and the lesson followed a cycle of practical activities followed by reflective discussion. 


\section{Results}

The use of headphones rather than the complex setup used for the previous lesson avoided the issues previously encountered, though it restricted performance and composition to groups of two. Again, the students responded well to the task, shared use of the iPad, and were seemed to perform. The starter activity of arranging the tuneblocks was met with great enthusiasm, and the students were able to work out the connection between the interface and the tuneblocks with no guidance (see Figure 9). This may be a result of playing tuneblocks directly from the iPad in the previous lesson, or it may be due to the intuitive nature of this as a mode of representation. During the performance, students typically played at a slow pace, following the tuneblock cards carefully, except for one pair, who tried to maintain a faster pace to keep up with the accompaniment of percussion bells they had decided upon. It was notable that one of the four pairs to perform following this activity had at least two tuneblocks in the wrong place, but performed the carol following this structure. This suggests that they were relying on the tuneblocks in the task and performance, rather than relying on their memory of the familiar tune.

\section{Figure 9. Arranging Tuneblocks into a Complete Structure}

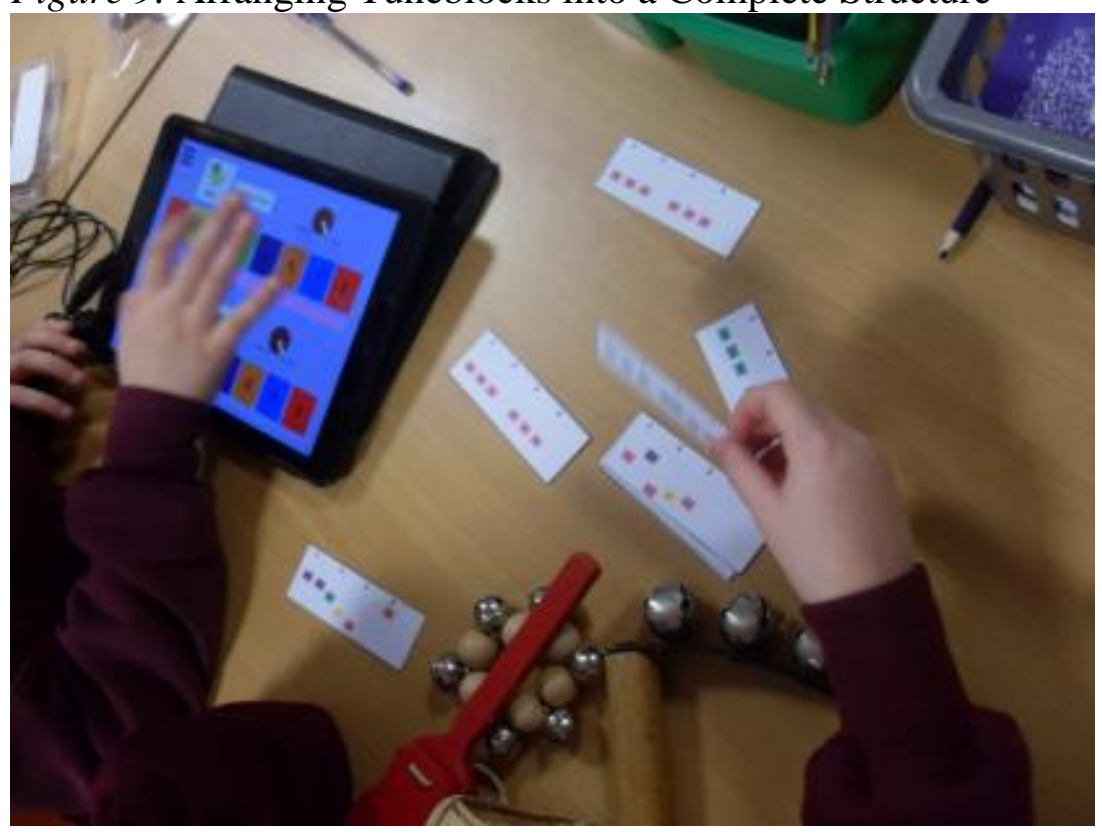

After a discussion about the lyrical themes of Christmas carols, a student suggested a first line for our carol: "snow is falling all around". Students were then asked to chant this over a four-beat bar to suggest a rhythm, with an interesting pattern eventually being decided upon by varying the durations of syllables. Another student suggested "snow is falling on the ground" as a second line, following the same rhythmic pattern and ending with a rhyme. A number of improvised melodies were then suggested for the first line. After reviewing the completed tuneblock carols, the students soon realised, that certain notes, 
particularly the red root notes at either end of the iPad keyboard, would make the melody sound finished while others would make it sound unfinished. When a melody which generally rose in steps was selected for the first line, another student made an interesting observation:

Student: "Could you do like, for "the ground", could you go a bit lower on the bottom one though..."

Me: "Yeah, so go lower on the last note? Why would we go lower on the last note?"

Other student: "Because it makes variation."

First student: "Because the ground is below"

The student had seen the opportunity to use the musical dimension of pitch to represent the lyrical theme, though the interrupting student's observation that this would give variation to the melody is also valid reasoning.

Figure 10. Lyrics and Numeric Melody Initially Drawing from "Jingle Bells", Before Moving In a New Direction

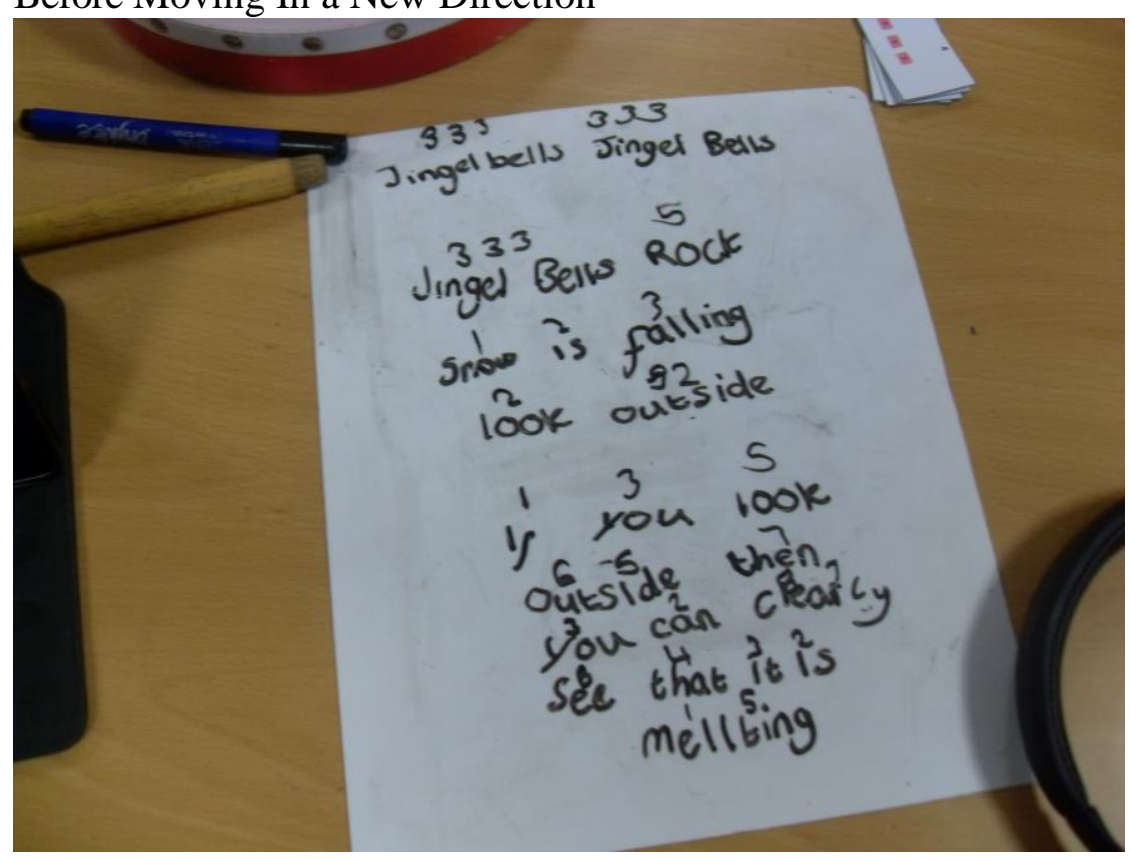


Figure 11. Lyrics and the Start of a Melody, Incorporating a Line From "Have Yourself A Merry Little Christmas" At the End

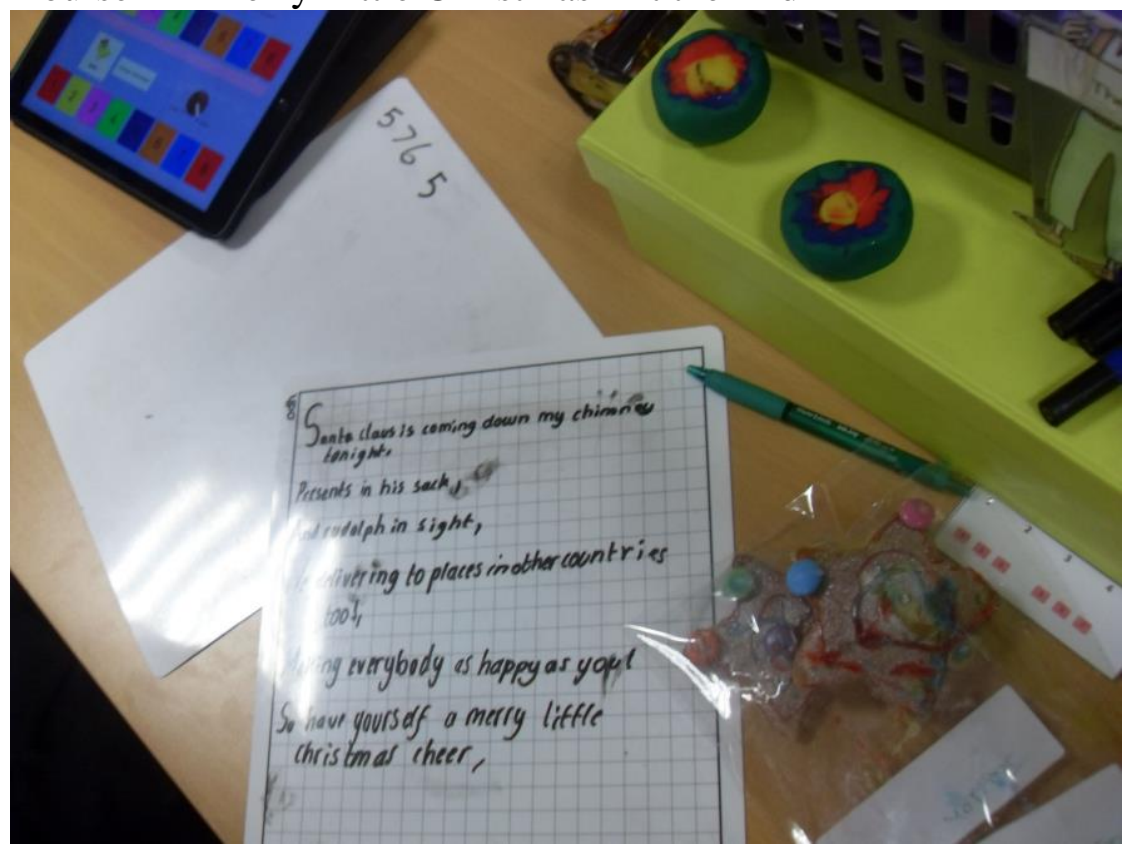

Figure 12. Two Melodies, Both Resolving On The Tonic (1 Or 8) - The Upper Line Distinguishes Between The Top And Bottom Note Rows On The Ipad Interface With The Letters "T" And "B", Suggesting That The Pupil Wanted To Switch Between Timbres

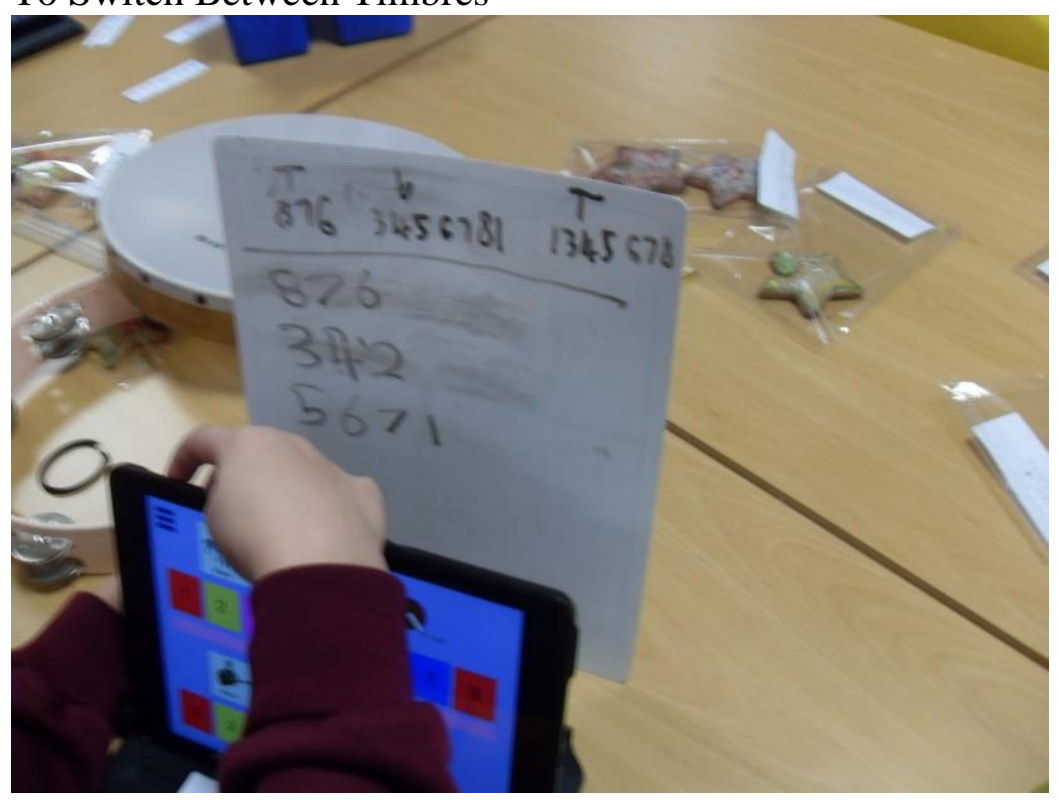

The students were then able to compose their own carols following this method. Many of the lyrics were borrowed from existing carols, and altered to fit a new structure or theme. This also frequently involved a rhythmic structure borrowed from one of the carols used in the starter activity (see Figures 10-12). Others had composed original melodies, often paying attention to melodic 
contour and the resolution of the tune by ending on an appropriate note (see Figure 13). There was evidence of the iPad interface leading to more varied compositions, as students attempted to use all of the notes on screen by following ascending and descending patterns (see Figure 14).

Figure 13. Original Melody and Accompanying Rhythm, Resolving On the Tonic

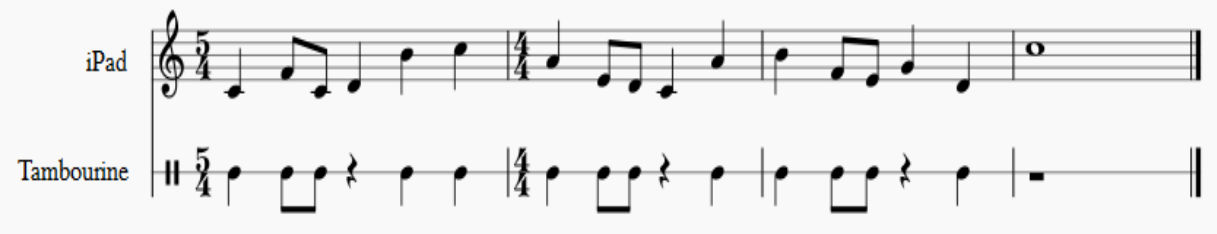

Figure 14. Ascending and Descending Melodic Pattern with a Straight Rhythmic Accompaniment

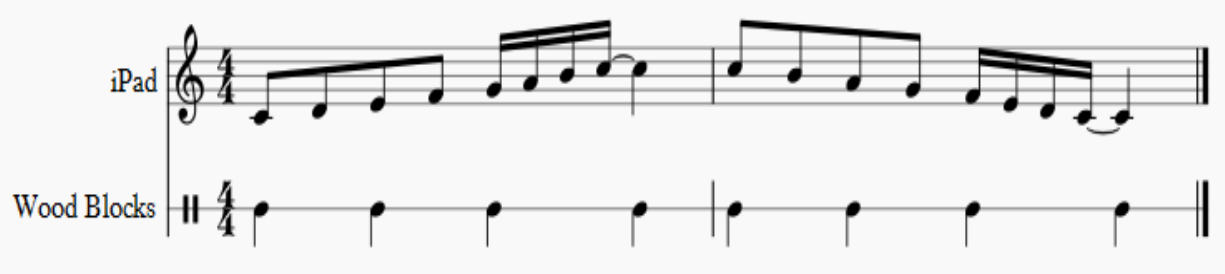

The composition of one student was characteristic of pealing bells, and followed a clear pattern, whereby the hands started at opposite ends of the iPad keyboard and worked towards one another. In this way, the student had devised a memorable kinaesthetic pattern (see Figure 15). When I attempted to repeat this performance to demonstrate the memorable nature of the pattern, the student was eager to again show how he had done it:

Me: "That was very memorable... I think I even remember how you played it..." [attempting to play the piece]

Student: [correcting me] "I'll show you. It went..."

Figure 15. Melodic Pattern Moving From the Outer Notes of the Ipad Keyboard to the Centre, Before Resolving On Both Outer Notes

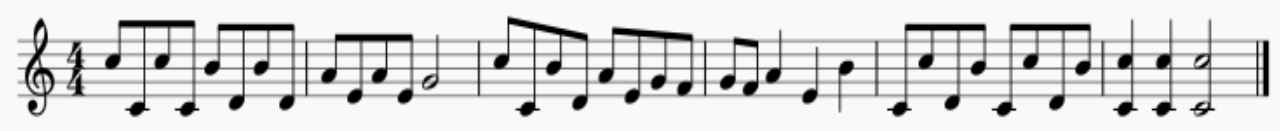

After the lesson, one student was copying their melody from their whiteboard onto a piece of paper, saying they wanted to work out how to play it on a recorder. I opened another app with a standard piano keyboard layout, and showed the student how the numbered notes matched up with the white keys, so they were able to write down the note names for their melody. They then told me that their parents had a keyboard and they would play the tune on the 
instrument when they got home. This is an example of the tablet acting as a scaffolding tool, and leading to independent learning on the part of the student. In retrospect, this approach might have been used at the end of the lesson so that all students had a notated version of their composition.

\section{Discussion}

Examples of deep learning are present in this study, defined by Fullan and Langworthy as instances of learning which "[develop] the learning, creating and "doing" dispositions that young people need to thrive now and in their futures' (2014, p. i), as well as what the authors term "new pedagogies", "models of teaching and learning" that are both enabled and accelerated by digital technology and resources, and that take place in environments that support "deep learning" (Clarke \& Svaneas, 2015, p. 7). The use of the tablet to facilitate performance through accessible modes of interaction and representation allowed the students to move further up what Borgo terms the "pyramid of processing" (2007, p.76) and engage with higher order skills such as improvisation, and the manipulation of musical dimensions. We were able to conduct a highly practical lesson, where no students became stuck on lower order musical skills such as repetition or memorisation, and instead focused on highly social, creative and exploratory musical activities. As well as meeting the intended lesson outcomes, several advanced aims from the National Curriculum were also met.

\section{How Might the Tablet Function within the Dynamic of the Classroom, in Terms of Facilitating "Performance in Solo and Ensemble Contexts"?}

The students successfully and confidently performed in larger groups, pairs and solo contexts. Whether playing iPads or percussion, the students moved rhythmically to keep in time, and displayed other kinaesthetic responses to musical dimensions, such as hunching when playing quietly. Kerchner (2000) observes that many children of the same age group participating in this study are "kinaesthetic listeners", responding to music with physical actions. That they respond in this way when playing a tablet is an indication of their readiness to employ it as a musical instrument, and also helped to co-ordinate the ensemble when students struggled to connect what they were playing with what they were hearing in the first lesson. Clearly, the setup used in the first lesson was not a sustainable solution, and other technical options should be explored in further research employing the tablet as an ensemble performance instrument.

\section{How the Tablet Might be used to Encourage "Increasing Accuracy, Fluency, Control and Expression"?}

As discussed, the accessible modes of representation and interaction employed gave the students a greater degree of control. The tuneblocks interface became a scaffold, or framework, from which the students could deviate whilst 
still maintaining sight of the original melody. This allowed them a further degree of control and accuracy in their invented patterns. We can also see evidence of this in the second lesson, where the simplicity of the interface led to fluent and confident performances. In this case, however, the tablet was relatively limited in terms of dynamic control, or the capacity for varied articulation. There are many functions of the touchscreen tablet which could be utilised to allow students a greater depth of control, such as touching the screen in different place for different dynamic levels, tilting to control certain parameters, or using a variety of gestures.

\section{How Might the Tablet Allow Pupils to Engage with the "Inter-Related Dimensions of Music" in their Performance and Composition?}

These lessons focused heavily on the use of musical dimensions to create mood or represent lyrical themes. Students were able to show their understanding of musical dimensions, but also how these related to their own performances and compositions, or those of others. This was, for the most part, something that the students were able to "jump ahead to", as they were able to perform the pieces following the starter activities and able to focus their attention on the creative development of their performance. However, I feel that there is far greater capacity to use a range of tablet functions to communicate musical dimensions, especially if we wish to explore the potential of the tablet as an expressive instrument in its own right and not merely a surrogate or scaffold for "real" instruments.

\section{How Might the Tablet Utilise Alternative Modes of Representation to Lead Pupils toward a Greater Understanding of Staff Notation?}

The use of tuneblocks was a highly successful component of both lessons, as was the use of game activities, such as the jigsaw puzzle starter of the second lesson, in promoting understanding of pitch and rhythmic relationships. This led toward a greater understanding of staff notation in at least one instance, as the student at the end of the second lesson learned the corresponding note names so that they could play their composition on other instruments. Simplified layouts of this kind, especially when interactive, can help children to understand the basic functions of musical notation. The touchscreen is an ideal interface for communicating this meaning, as it can effectively combine the functions of score and instrument. In the first lesson, the students literally played the score, by following the onscreen notations, later deviating from this score to produce original musical ideas. By contrast, in the second lesson, the students used the tuneblock cards as scores, or wrote their own on whiteboards.

\section{Conclusion}

While this study has presented some results that may tell us how the tablet 
can function in classroom performance contexts, this is a very wide and very new area of research, and this study has various limitations. We have only looked at a small sample of Year 5 students. Further research is needed across different age ranges, to build a wider picture of how children can utilise tablets for musical learning at different ages. We have also focused mainly on a few specific aims from the National Curriculum, which, presents many possible approaches when using a versatile tool such as the tablet. In addition, further research is needed to explore how the tablet is used by both specialist and generalist teachers in music lessons. As a trained music teacher, I delivered the classes in this study, but it is worth noting that the lessons required no performance or other specialist musical demonstrations from me, while the children were all able to both perform and compose.

There are also many more avenues for exploration with regard to the functions of the tablet. This study mainly focused on simple touchscreen interfaces. More complex multi-touch functions, such as pinching to magnify or rotate portions of the screen, may be used as modes of musical interaction. So too could other modes of interaction, such as shaking, tilting, and even less common modes of input such as voice activation. In particular, research is needed to assess how such functions may make musical performance more accessible for students with various physical or learning requirements. It may be that modes of digital interaction present unique solutions to musical expression and fluency.

Within this research project, further studies using the tablet as a classroom instrument will be conducted at key stage 2 . The proposed next step is to explore how whole-class performance might take place, and how further functions of the iPad can be utilised for musical expression. This will take the form of an "iPad Orchestra", and will most likely focus on the arrangement and performance of a popular song. In this study, we would like to ensure that students have access to a range of apps and interfaces, allowing them to explore different sounds and modes of interaction. These may again be made in MobMuPlat, as this would allow us to colour-code the interfaces to differentiate notes or chords, and possibly utilise other functions, such as wireless communication between devices for the purposes of performance cues. This would also allow us to share these interfaces as a collection of files, which could be saved on an iPad and opened within the freely available app. We also intend to try using a range of downloaded free apps, though the challenges of co-ordinating the use of very disparate interfaces may require much more rehearsal time. One of the advantages of this approach, however, is that it may encourage students to source their own apps, leading to creative inquiry that may extend outside of the classroom. Finally, the issue of amplification still presents problems, as we would like to find a solution that works in a classroom context without excessive specialist equipment. As the headphone splitters proved an inexpensive and useful resource, these might be used to consolidate the outputs from two or more iPads. In this way, the number of tablets used for this study could be played through an 8-track mixer, which presents a reasonably affordable solution. 


\section{Acknowledgements}

Funded by the Arts \& Humanities Research Council UK, through the Northwest Consortium Doctoral Training Partnership.

\section{References}

Bamberger, J. (1996). Turning music theory on its ear: Do we hear what we see; Do we see what we say?. International Journal of Computers for Mathematical Learning, $1(1), 33-55$.

Bamberger, J. S., \& Hernandez, A. (2000). Developing musical intuitions: A projectbased introduction to making and understanding music. Oxford University Press, USA.

Biasutti, M., Hennessy, S., \& de Vugt-Jansen, E. (2015). Confidence development in non-music specialist trainee primary teachers after an intensive programme. British Journal of Music Education, 32(2), 143-161.

Borgo, D. (2007). Free jazz in the classroom: An ecological approach to music education. Jazz perspectives, 1(1), 61-88.

Clarke, B., Svanaes, S., \& Zimmermann, S. (2013). One-to-one tablets in secondary schools: an evaluation study. Tablets for schools.

Clarke, B., \& Svanaes, S. (2014). An updated literature review on the use of tablets in education. Tablets for Schools. UK: Family Kids \& Youth.

Clarke, B., \& Svanaes, S. (2015). Updated review of the global use of mobile technology in education, London.

Criswell, C. (2011). Technology on the Horizon. Teaching Music, 18(5), 30.

Daubney, A., \& Mackrill, D. (2013). Music technologies in education - playing the home advantage. Music Education UK and Music Education Asia magazines.

Daubney, A., \& Mackrill, D. (2015). Planning music in the national curriculum. Planning the Primary National Curriculum: A complete guide for trainees and teachers, 249.

Department for Education and Department for Culture, Media and Sport, (2011). The importance of music: A national plan for music education. Retrieved from www. gov.uk/government/uploads/system/uploads/attachment_data/file/180973/DFE-0 0086-2011.pdf

Department for Education (DfE) (2013). Music programmes of study: key stages 1 and 2. National Curriculum in England. Retrieved from http://bit.ly/2euEfJY.

de Vries, P. (2013). Generalist teachers' self-efficacy in primary school music teaching. Music Education Research, 15(4), 375-391.

Fels, S., Gadd, A., \& Mulder, A. (2002). Mapping transparency through metaphor: towards more expressive musical instruments. Organised Sound, 7(2), 109-126.

Fullan, M., \& Langworthy, M. (2014). A rich seam: How new pedagogies find deep learning. MaRS Discovery District.

Garvis, S. (2013). Beginning generalist teacher self-efficacy for music compared with maths and English. British Journal of Music Education, 30(1), 85-101.

Hallam, S., Burnard, P., Robertson, A., Saleh, C., Davies, V., Rogers, L., \& Kokatsaki, D. (2009). Trainee primary-school teachers' perceptions of their effectiveness in teaching music. Music Education Research, 11(2), 221-240.

Hallam, S., Creech, A., \& McQueen, H. (2017). Can the adoption of informal approaches to learning music in school music lessons promote musical progression?. British 
Journal of Music Education, 1-25.

Holden, H., \& Button, S. (2006). The teaching of music in the primary school by the non-music specialist. British Journal of Music Education, 23(1), 23-38.

Kerchner, J. L. (2000). Children's verbal, visual, and kinesthetic responses: Insight into their music listening experience. Bulletin of the Council for Research in Music Education, 31-50.

Little, F. (2009). An exploration into the uptake rates of GCSE music with a focus on the purposes of music in school (Doctoral dissertation, Durham University).

Marsh, J., Plowman, L., Yamada-Rice, D., Bishop, J. C., Lahmar, J., Scott, F., \& Thornhill, S. (2015). Exploring play and creativity in pre-schoolers' use of apps: Final project report. Technology and Play.

Musicians' Union (MU) (2014). Music education hubs: The real story so far. Retrieved from http://bit.ly/2eoOuMj.

Ofsted, (2012). Music in schools: wider still, and wider. Retrieved from http://bit.ly/ 2euAu71.

Ofsted, (2013). Music in schools: what hubs must do. Retrieved http://bit.ly/2wsvchd.

Papert, S. (1980). Mindstorms: Children, computers, and powerful ideas. Basic Books, Inc..

Paynter, J. (1982). Music in the Secondary School Curriculum: Trends and developments in class music teaching. Cambridge university press.

Pegrum, M., Oakley, G., \& Faulkner, R. (2013). Schools going mobile: A study of the adoption of mobile handheld technologies in Western Australian independent schools. Australasian Journal of Educational Technology, 29(1).

Riley, P. (2013). Teaching, learning, and living with iPads. Music Educators Journal, $100(1), 81-86$.

Riley, P. (2016). iPad apps for creating in your general music classroom. General Music Today, 29(2), 4-13.

Ruismäki, H., Juvonen, A., \& Lehtonen, K. (2013). The iPad and music in the new learning environment. The European Journal of Social \& Behavioural Sciences, 6(3), 1084-1096.

Russell-Bowie, D. (2009). What me? Teach music to my primary class? Challenges to teaching music in primary schools in five countries. Music Education Research, $11(1), 23-36$.

Sangani, K. (2013). BYOD to the classroom [bring your own device]. Engineering \& Technology, 8(3), 42-45.

Santos, I. M. (2013). Use of students' personal mobile devices in the classroom: Overview of key challenges. In E-Learn: World Conference on E-Learning in Corporate, Government, Healthcare, and Higher Education (pp. 1585-1590). Association for the Advancement of Computing in Education (AACE).

Seddon, F., \& Biasutti, M. (2008). Non-music specialist trainee primary school teachers' confidence in teaching music in the classroom. Music Education Research, 10(3), 403-421.

Smith, N., Sutcliffe, C., \& Sandvik, L. (2014). Code club: bringing programming to UK primary schools through scratch. In Proceedings of the 45th ACM technical symposium on Computer science education (pp. 517-522). ACM.

Song, Y. (2014). "Bring Your Own Device (BYOD)" for seamless science inquiry in a primary school. Computers \& Education, 74, 50-60.

Song, Y. (2016). "We found the 'black spots' on campus on our own": development of inquiry skills in primary science learning with BYOD (Bring Your Own Device). Interactive Learning Environments, 24(2), 291-305.

Stunell, G. (2010). Not Musical? Identity Perceptions of Generalist Primary School 
Teachers in Relation to Classroom Music Teaching in England. Action, Criticism, and Theory for Music Education, 9(2), 79-107.

Tierney, S. (2012). Bring your own device to school. Microsoft Education.

Vygotsky, L.S. (1962). Thought and language. MIT Press.

Williams, D. A. (2014). Another perspective: The iPad is a REAL musical instrument. Music Educators Journal, 101(1), 93-98.

Wilson, A., Hainey, T., \& Connolly, T. M. (2013). Using Scratch with primary school children: an evaluation of games constructed to gauge understanding of programming concepts. International Journal of Game-Based Learning (IJGBL), 3(1), 93-109.

Wilson, A., Hainey, T., \& Connolly, T. (2012). Evaluation of computer games developed by primary school children to gauge understanding of programming concepts. In European Conference on Games Based Learning (p. 549). Academic Conferences International Limited.

Wyatt, A. K., \& Hope, C. (2013). Animated Music Notation on the iPad (Or: Music stands just weren't designed to support laptops). In Proceedings of the 2013 ICMC Conference. (pp. 201-207). 
